\title{
Congestion Management and Transmission Line Loss Reduction using TCSC and Market Split Based
}

\author{
Jasjeet Singh, Harpreet Kaur
}

\begin{abstract}
Due to increasing power demand in a deregulated power system, the stability of the power system may get affected and sometimes it may also cause congestion in the transmission lines of power networks. It is a major issue for a deregulated power system and its management provides a competition environment to different market players. In this paper, market split based approach is used to tackle the problem of congestion which split the system into zones. Locational Marginal Pricing (LMP) method is used to access the prices at different buses. The objective is to minimize the congestion effect. DC optimal power flow based system is used to solve such type of problem. TCSC (Thyristor-Controlled Series Compensation), FACTS (Flexible Alternating Current Transmission System) device is used to reduce the losses in a transmission system. Market splitting based approach is effective to manage the prices at different buses and system stability is increased by using TCSC. The whole work is carried out on IEEE 14 bus system.
\end{abstract}

Index Terms: Locational marginal pricing (LPM), TCSC, DC optimal power flow, Congestion management

\section{INTRODUCTION}

In a deregulated power system, scale of economy is changed because the entities in a regulated power system are separated. The objective of deregulation is to start the competition between market players and provide the maximum benefits to the consumers. In this competitive market generating units and customers send their bids to the market operator and market operator set a market at a single price. So the seller and buyer get the same price. But the rapid increase of a power demand provides a complexity to transmission system and there are chances to congestion in the system and it occurs due to increase in load demand, outage of system, equipment failure and improper conditioning for generators [2]. Due to Congestion in a power system, the system gets unstable and inefficient. So congestion management is a major challenge for reliable and secure operation. In a deregulated power system generation side congestion management approaches are used to mitigate the problem of congestion, because generators are more attention in deregulated power system. Many researchers do their work to tackle the problem of congestion.

Revised Manuscript Received on June 15, 2019.

Jasjeet Singh, Harpreet Kaur Electrical engineering, Chandigarh University Gharuan,Mohali, India
Many techniques are feasible for congestion management. Distribution generators (DGs) are optimally placed for congestion management is given in [1]-[2]. By providing the DG at a particular location in a transmission system the routes of the power flow are redistributed and the congested lines are relived. In [3]-[10] transmission planning of the deregulated power industry to meet the requirement is given. Monte Carlo simulation is used to finding the plan for optimal transmission expansion. Optimal placement of FACTS device to manage congestion is given in [4]-[13]. TCSC is used to controls power flow in lines by reducing the power flow in heavily loaded line which gives the results such as stability improvement, system reliability, increasing load ability and low system losses. In [6] cost-worth approach is used for sizing and optimal location of distribution resources (DRs). For stability problems in congestion management optimal flow related constraints are given in [7]. Sensitivity based approaches for congestion management are given in [8]-[15]. Real and reactive power sensitivity index is used in zonal / cluster based approach for congestion management [9]. In [18] Genetic algorithm based approach is used to calculate the LMPs at all the buses for DCOPF models. LMP technique is given for the placement of and sizing of the facts devices [12]-[16]. Congestion is managed by using marketing splitting based approach is given in [14]. Krill hard optimization technique is given for the placement and configuration of facts device [17].

Market splitting based approach is used in this paper to tackle the problem of congestion. In this approach different zones are taken to divide the system. LPM is used to find the prices at different generating station and find the LMPs at buses. TCSC device is used to reduce the transmission line losses. This study is being done by using IEEE 14 bus system.

DCOPF is done by using a program in MATLAB. LMPs are calculated by using FMINCON function in a MATLAB environment. Results are compared with program run in MATPOWER which is toolbox of MATLAB. For this problem two cases are considered without congestion case and with congestion case. In congestion case the area is divided into different zones. The LMPs are calculated by using an average value of prices from different buses. The parameters of different elements in DCOPF are used to find the actual load flow by using MiPOWER software which gives the actual line flow and losses in a transmission system. Base case and congestion case are formulated in MiPOWER software. TCSC facts device

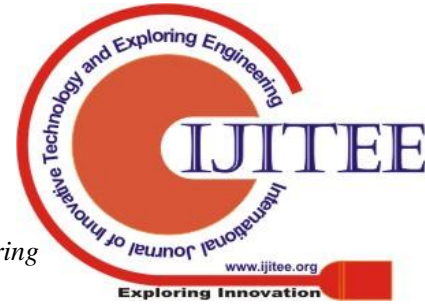


is used to reduce the losses in a transmission line for congestion case.

Following objects are done in this paper:

- To manage the Congestion of transmission lines system in deregulated power industry by the use of market splitting based method.

- To reduces the losses in a transmission lines and increasing the efficiency of whole system.

The rest part of this paper is presented as follow: Section2. Modeling of a system, Section3. Congestion management, Section4. Load flow analysis for deregulated power system using MiPOWER software. Section5. Conclusion of this paper.

\section{Problem formulation AND MODELing OF A SYSTEM FOR CONGESTION MANAGEMENT}

\section{A. Market splitting based approach.}

Market splitting based congestion management approach is used to reduce the generation cost. In this work two cases are considered such as without congestion and with congestion. It has seen in this research work that when congestion is not occurs in the system; the prices at each bus are same and in congestion case the prices are different at each bus thus the system is divided into separate zones. To find the prices at all the buses, mathematical model of this type problem is expressed as formulation of DC optimal power flow (OPF). The values of a DCOPF are normally expressed in per unit (p.u) so the magnitudes of variable in this are nearly equal. So in DCOPF assumptions such as (i) losses can be neglected, (ii) magnitudes of the voltage for various buses is considered as one per unit are considered but (iii) flows of reactive power in a transmission system is not considered. DCOPF is done using Matlab environment and the results from this are compared with program run in MATPOWER. MiPOWER software is used to find the actual line flow of the system.

\section{B. Mathematical modelling:}

The model used to formulate the DCOPF problem in a Matlab is given as follow. The assumptions are considered for DCOPF. The objective function to reduce the cost function for proposed problem is given as follow.

$\mathrm{F}=\left(\alpha_{x} \times P_{g_{x}}^{2}+\beta_{x} \times P_{g_{x}}+\gamma_{x}\right)$

and the decision variables are $\left(\lambda_{1}, \lambda_{2}, \ldots \ldots \ldots, \lambda_{z^{*}}, P_{g_{1}} P_{g_{2}, \ldots x} P_{g_{x}}\right)$

(2)

The constraints of the objective function are as follow:

1. Power balance constraint at each node of the system

$$
\begin{aligned}
& P_{g_{m}}-P_{d_{m}}=\sum_{(n=1)}^{z} B_{m n}\left(\lambda_{m}-\lambda_{n}\right) \\
& \quad \text { for } m=1,2,3_{x, x} z
\end{aligned}
$$

Reactance data is used to obtain the susceptance matrix from line impedance. The program is written in the MATLAB to find the susceptance matrix.

2. Generator limit constraint for operation

$$
P_{G_{x}}^{\min } \leq P_{G_{x}} \leq P_{G_{x}}^{\max }
$$

3. Line flow constraint

$$
L_{\mathrm{ij}}^{\min } \leq L_{\mathrm{ij}} \leq L_{\mathrm{ij}}^{\max } \quad \mathrm{ij}=1,2, \ldots \ldots \ldots \ldots . \mathrm{jk}
$$

4. Bus voltage limit constraints

$$
V_{m}^{\min } \leq V_{m} \leq V_{m}^{\max }
$$

5. Voltage angle constraints

$$
\lambda_{m}^{\min } \leq \lambda_{m} \leq \lambda_{m}^{\max }
$$

fmincon function as a non linear programming solver is used to find the prices at the different buses for base case (no congestion in transmission line) used in MATLAB software. fmincon means to find minimum of constrained nonlinear multivariable function which is used to minimize the cost function $(\mathrm{F})$.

linear constraints of fmincon function

$$
l_{e q} . X=K_{e q}
$$

\section{Selection of a TCSC parameters}

TCSC is a series compensating device used to reduce the losses by compensating the reactance in a transmission line. TCSC is used due to it can dynamically vary compensation whereas conventional series capacitor has fixed compensation. Fig. 1 shows the diagram of the TCSC.

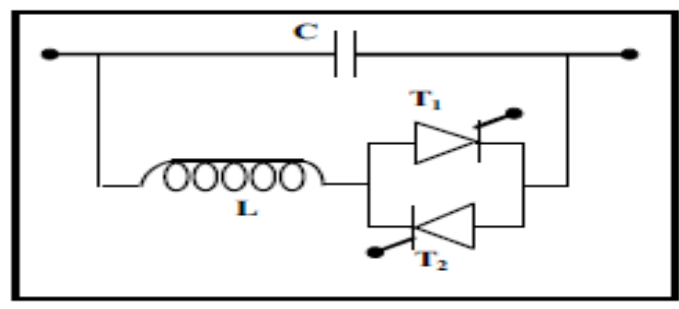

Figure 1. Block Diagram of TCSC Device.

TCSC has a series compensating compensator (C) is connected parallel to the thyristor controlled reactor (TCR)[4], Where TCR is a variable inductive reactor $\left(\mathrm{X}_{\mathrm{L}}\right.$ $(\alpha))$ and is shown in fig 2 .

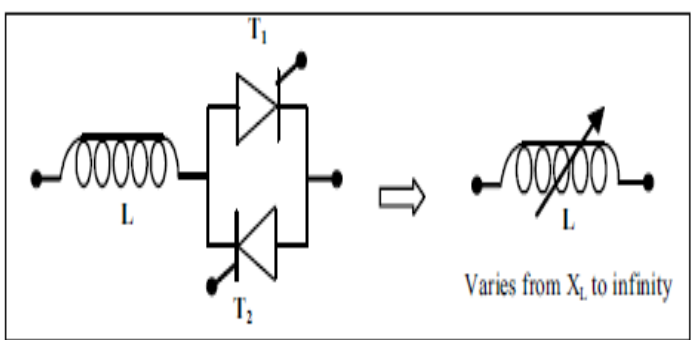

Figure 2. Basic Circuit of TCR 
Mathematical values of TCR are is given below

$$
\begin{gathered}
X_{\mathrm{L}}(\tau)=\mathrm{X}_{\mathrm{L}} \frac{\pi}{\pi-2 \alpha-\sin \alpha} \\
\mathrm{X}_{\mathrm{C}}=\frac{1}{2 \pi \mathrm{fC}}
\end{gathered}
$$

Where

$$
\begin{gathered}
\mathrm{X}_{\mathrm{L}}(\tau)=\text { variable inductive reactor } \\
\alpha=\text { firing angle of inductive reactor } \\
0<\alpha<90
\end{gathered}
$$

The equivalent diagram of TCSC device is shown in fig 3.

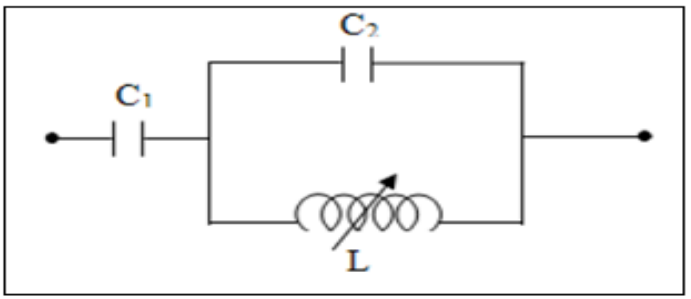

Figure 3. Basic Circuit of TCSC

Where

$\mathrm{C}_{1}=$ series capacitance of TCSC

$\mathrm{C}_{2}=$ shunt capacitance of TCSC to the variable inductor $\mathrm{L}=$ variable inductor

$X_{\text {TCsc }}(\tau)=X_{C}+C_{1}(2(\pi-\tau)+\sin (2(\pi-\tau)))-$ $C_{2} \cos ^{2}(\pi-\tau)(\omega \tan (\omega(\pi-\tau))-\tan (\pi-\tau)$

Where the values of $\mathrm{C}_{1}, \mathrm{C}_{2}$ and $\mathrm{X}_{\mathrm{LC}}$ are calculated as $\mathrm{C}_{1}=\frac{\mathrm{X}_{\mathrm{C}}+\mathrm{X}_{\mathrm{LC}}}{\mathrm{T}}$

$C_{2}=4 \frac{x_{L C}^{\frac{\pi}{2}}}{x_{\mathrm{L}} \pi}$

$\mathrm{X}_{\mathrm{LC}}=\frac{\mathrm{x}_{\mathrm{C}} \mathrm{x}_{\mathrm{L}}}{\mathrm{x}_{\mathrm{C}}-\mathrm{X}_{\mathrm{L}}}$

$\omega=\sqrt{\frac{\mathrm{X}_{\mathrm{c}}}{\mathrm{X}_{\mathrm{L}}}}$

\section{Locational marginal pricing}

LMP method is used to find the congestion prices in a reconstructed industry. LMP is a marginal cost which supplies next increment in the electrical energy in the specific bus. It consists of a component like marginal energy component, congestion component and marginal loss component by considering the effect of generation marginal cost and physical aspects of transmission power system[2].

\section{- Mathematically model of LMP for base case:}

In this model the prices are same for every bus. This gives the LMPs for lossless DCOPF.

$$
\begin{aligned}
L M P_{k} & =\frac{d C_{k}}{d P_{k}} \\
\mu_{k} & =\frac{\Delta C_{k}}{\Delta P_{k}} \\
\mu_{j} & =\mu_{e}+\mu_{\text {loss }}+\mu_{\text {cong }}
\end{aligned}
$$

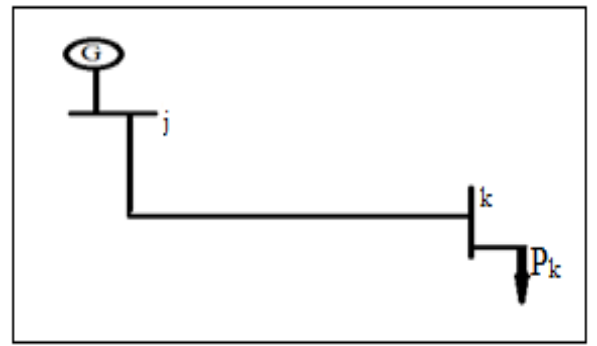

Figure 4. Single Line Diagram to Explain LMP.

\section{- LMPs with the effect of congestion}

Due to the congestion in a transmission system, LMPs values are different at every bus, so the system is split into different areas by considering the LMPs values and the value of LMP for particular zone is calculated by using equation (19). For example the $\mathrm{M}$ bus system is splited into $\mathrm{N}$ zones by considering the effect of congestion. The LMP of the $\mathrm{N}^{\text {th }}$ zone is given as:

LMP for $\mathrm{N}^{\text {th }}$ zone $=\frac{\sum_{x=1}^{D} L M P_{x} \times P_{D_{x}}}{\sum_{x=1}^{h} P_{D_{x}}}$

\section{E. Methodology for solution}

DCOPF is used to solve the present problem in a MATLAB environment and the Results of DCOPF are used to find the actual line flow in a transmission system by using Mipower software.

\section{The Algorithm to solve proposed Methodology:}

1. Obtain the DCOPF in a MATLAB by using the fmincon function without considering the congestion in a line and compare the results of MATLAB function with the MATPOWER IEEE 14 bus system.

2. Compare the LMP values at different buses.

3. If congestion is occurs in a transmission line then runs the program in a MATPOWER and obtains the LMPs at different buses.

4. Market split based approach is used to differentiate the zones by taking the values of LMPs which are near to each other.

5. The specific value of LMP for each zone is obtained by taking the average of LMPs value of particular zone (19)

6. Load flow analysis is obtained by using the Newton-Raphson method in a MiPOWER to find the actual power/line flow and the status of a power system.

7. Solve the LFA for without and with congestion cases.

8. TCSC device add in the transmission network to reduce the losses in a transmission system.

9. Obtain the LFA with TCSC for congestion case in Mipower.

Find locational marginal prices in case of congestion when TCSC is added.

III. CONGESTION MANAGEMENT IN A

Published By: 


\section{DEREGULATED POWER SYSTEM}

In a deregulated power market if the congestion is occurs in a transmission system then the contractual flow with available capacity of a transmission system is calculated. If the flow is more than available capacities then the market is split into different areas and prices are adjusted in the zones. If the available capacity is not exceed then the prices are same in all areas. The prices are more in those areas in

which the generation is low and prices are less in those areas in which generation is more. Then there is need to match the needed flow in the transmission system to overcome this problem. Market splitting based approach is used to tackle this type of problem. Then the prices are different in different zones. This approach is done by using MATPOWER and MATLAB software.

\section{TEST CASE AND RESULTS}

\subsection{No Congestion Case}

DCOPF non linear programming solver i.e. fmincon function is used to find the LMPs for the base case (no congestion case). In this case we are studying the LMPs for no congestion case. It is found that the LMPs are same at all the buses for no congestion case. The LMPs are given in \$/MW-hr and LMPs at each bus is 39.03 \$/MW-hr. Then we can say that the market is cleared at a single price. The LMPs for different buses is shown in figure 5 .

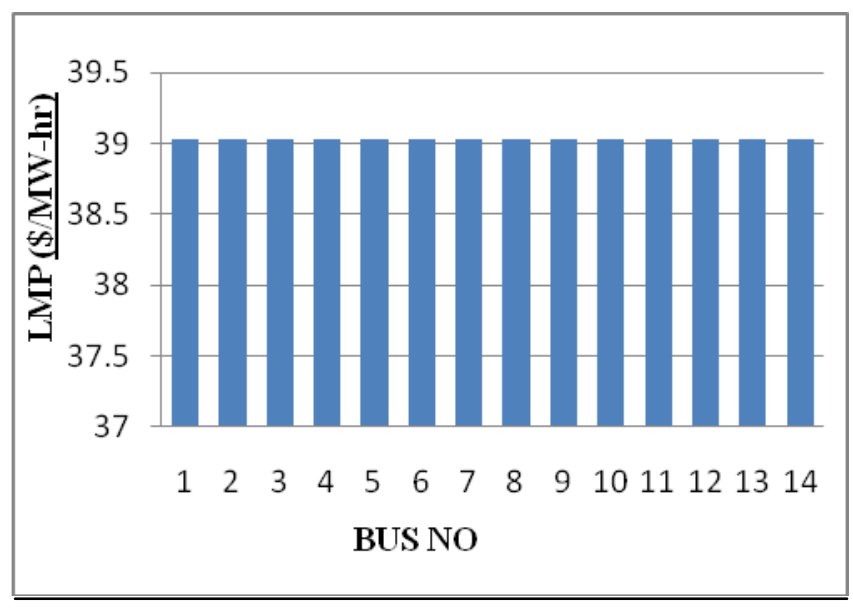

Figure 5. LMPs For No Congestion Case

\subsection{Congestion case without TCSC}

In the congestion case the capacity of the transformer connected between the buses 4 and 5 is limited to $38 \mathrm{MW}$. When congestion is not considered, $42.8 \mathrm{MW}$ was flowing through the transformer in the base case. By considering the congestion in a transformer the result of LMPs for different buses is shown in the Fig 6.

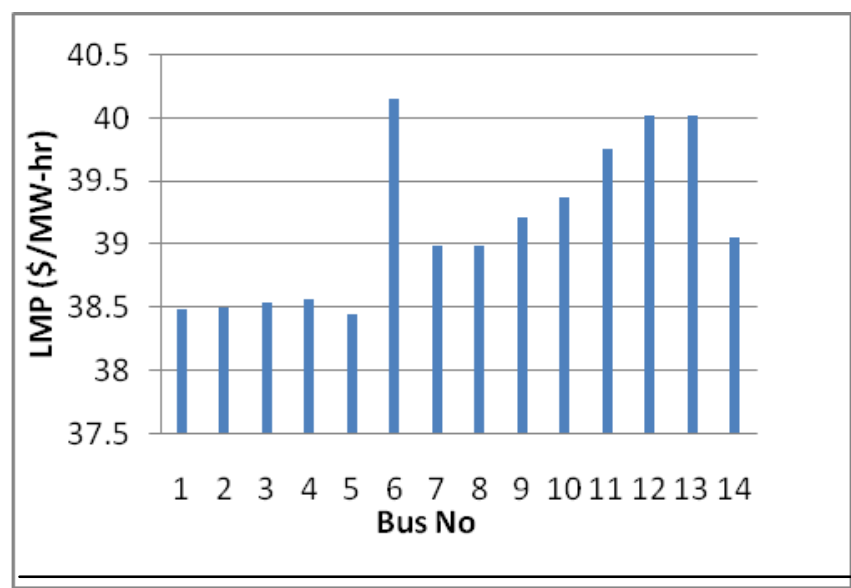

Figure 6. LMPs for Congestion Case without Market Splitting

Due to congestion occurs in a transmission line the LPMs are different at every bus and market is cleared at different prices. Then the system is divided into three zones by taking the average of LMPs of different buses in which LMP are near to each other. The bus system for different zones is show in figure 7 .

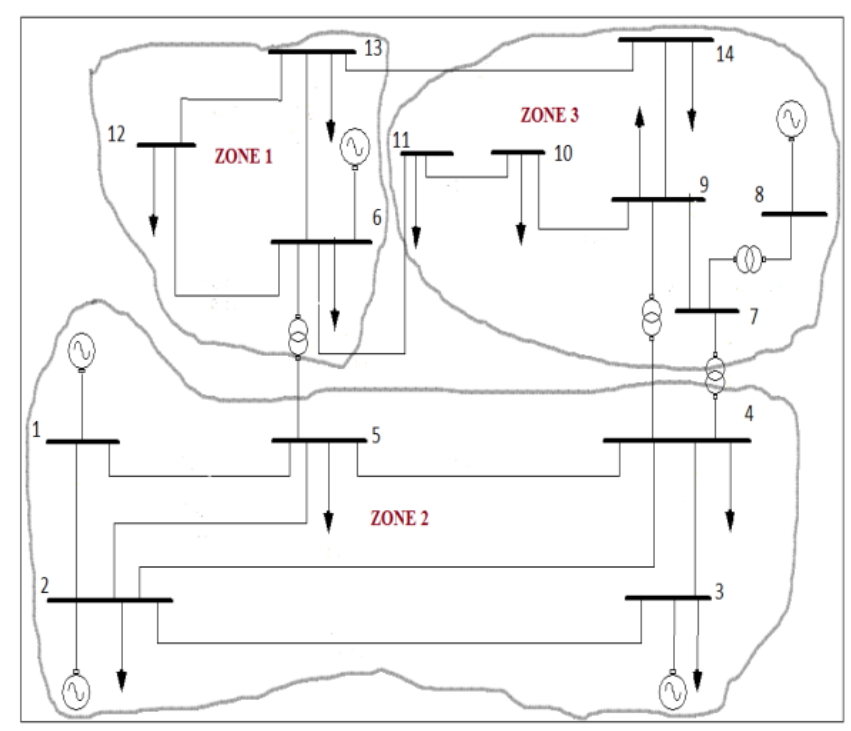

Figure 7. IEEE 14 Bus System with Different Zones.

Fig. 8 represents the 14 bus system which is separated into three different zones. The separation of these zones is done by taking the values of LMPs for congestion case.

The LMP for different zones is calculated by using an equation (17). Table 1 shows the LMPs for different zones.

Table 1. LMP for Different Zones after Splitting Market without TCSC

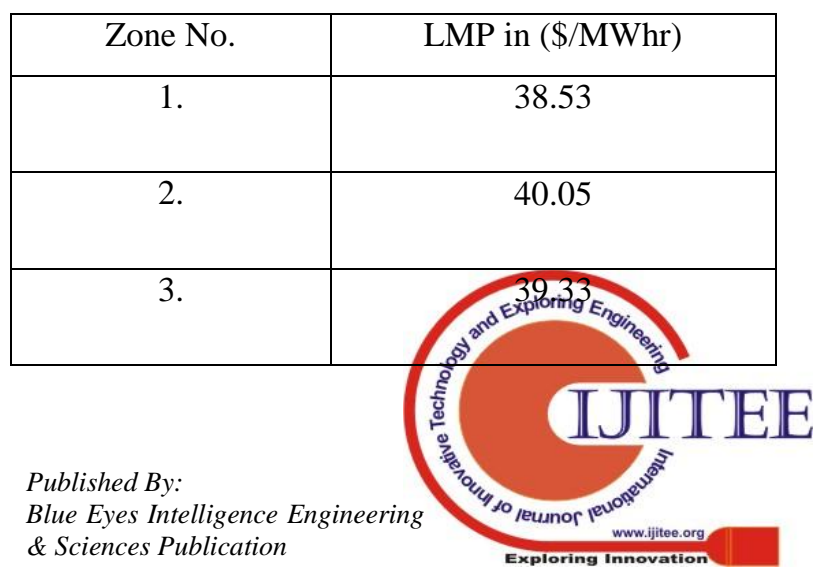


Market split approach based LMPs for different buses are shown in fig 8 . In this system the prices for different zones are different and the prices of buses in respective zone are same.

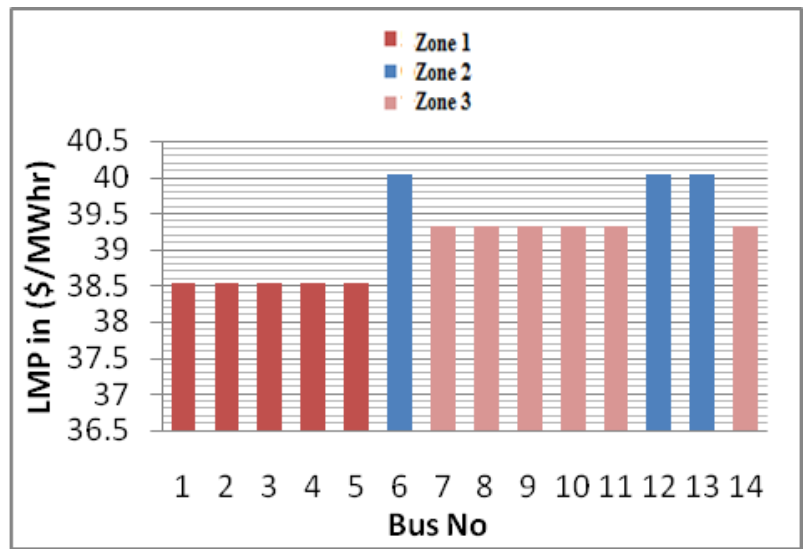

Figure 8. LMPs Market Splitting approach for Congestion Case.

\section{Results and discussion:}

In no congestion case there are two generators generate the electricity i.e. generator 1 and 2. Generator 1 generates 220.97 MW and generator 2 generates 38.03 MW. In this case the LMPs for all the buses are same ie. 39.03. In congestion case three generators generate the electricity. Generator 1 generates 214.85 MW, generator 2 generates $37 \mathrm{MW}$ and generator 4 generates $7.15 \mathrm{MW}$. In this case the LMPs for all generators are different. The LMPs for all the cases is shown in fig 9.

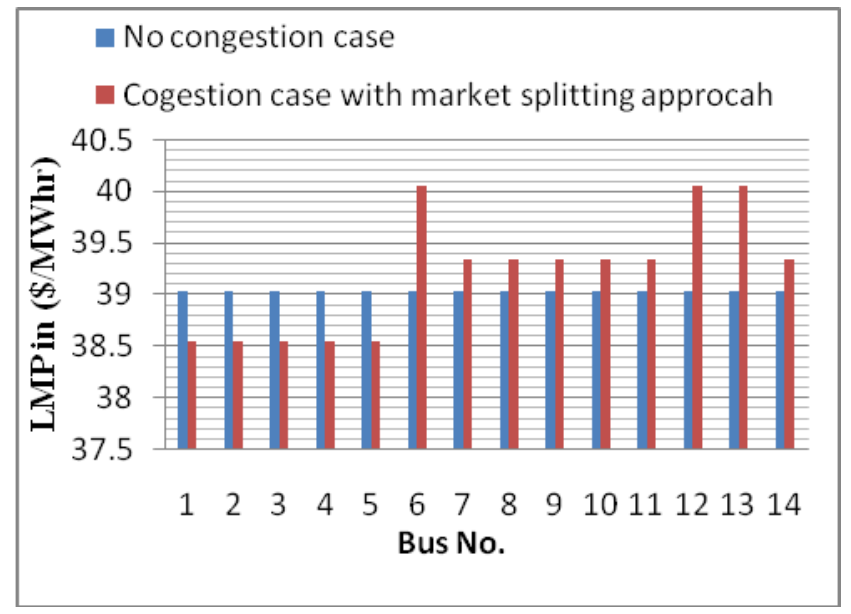

Figure 9. Comparison of LMPs for all cases.

If you are using Word, use either the Microsoft Equation Editor or the MathType add-on (http://www.mathtype.com) for equations in your paper (Insert | Object | Create New | Microsoft Equation or MathType Equation). "Float over text" should not be selected.

\section{LOAD FLOW ANALYSIS FOR DEREGULATED POWER SYSTEM USING MIPOWER SOFTWARE}

MiPOWER is software used to solve the problems of power system. This system is used to cover various aspects such as steady state analysis, security, protection and reliability for the power system. It helps us to planning and operating the system. This system accepts the worldwide standards such as ANSI, IEEE, IEC and etc. This system is proved for field and time testing. The actual flow in a transmission is obtained by using this software.

NR method is used to find the load flow studies. The following approach is done on the MiPOWER software to find the load flow studies for with/without congestion and the case with TCSC addition in congestion case.

\section{Modeling of a transmission system}

1. Transmission line modelling:

In this the bus voltages at bus $m$ and $n$ are $V_{m} \angle \lambda_{m}$ and $V_{n} \angle \Omega_{n}$ respectively. Real and reactive power flow between bus $\mathrm{m}$ and $\mathrm{n}$ are $P_{\mathrm{mn}}$ and $Q_{\mathrm{mn}}$ respectively similarly between buses $\mathrm{n}$ and $\mathrm{m}$ are $P_{\mathrm{nm}}$ and $Q_{\mathrm{nm}}$ respectively.

$$
\begin{aligned}
& P_{m n}= \\
& V_{m}^{2} G_{m n}-V_{m} V_{n}\left[G_{m n} \cos \left(\eta_{m n}\right)+\right. \\
& B_{m n} \sin \left(\lambda_{m n}\right)
\end{aligned}
$$

$$
\begin{gathered}
Q_{m n}=-V_{m}^{2}\left(B_{m n}+B_{s h}\right)-V_{m} V_{n}\left[G_{m n} \sin \left(\lambda_{m n}\right)+\right. \\
\left.B_{m n} \cos \left(\eta_{m n}\right)\right]
\end{gathered}
$$

$$
\begin{aligned}
& P_{m m}= \\
& V_{n}^{2} G_{m n}-V_{m} V_{n}\left[G_{m n} \cos \left(\eta_{m n}\right)+\right. \\
& B_{m n} \sin \left(\lambda_{m n}\right)
\end{aligned}
$$

$$
\begin{gathered}
Q_{m m}=-V_{n}^{2}\left(B_{m n}+B_{s h}\right)-V_{m} V_{n}\left[G_{m n} \sin \left(\eta_{m n}\right)+\right. \\
B_{m n} \cos \left(h_{m n}\right)
\end{gathered}
$$

\section{Modelling of TCSC}

Power loss function is given as

$P_{L}=\sum_{p=(m n)}^{k} x=1 g_{x}\left\{V_{m}^{2}+V_{n}^{2}-2 V_{m} V_{n} \cos \lambda_{m n}\right.$

Inequality constraints

$$
\begin{aligned}
& V_{m}^{\min } \leq V_{m} \leq V_{m}^{\max } \\
& Q_{G_{x}}^{\min } \leq Q_{G_{x}} \leq Q_{G_{x}}^{\max }
\end{aligned}
$$

Reactive power associated with compensator TCSC $Q_{\text {comp }}^{\min } \leq Q_{G_{x}} \leq Q_{\text {comp }}^{\max }$

Tap changer setting is given by

$$
T_{\mathrm{m}}^{\min } \leq T_{\mathrm{m}} \leq T_{\mathrm{m}}^{\max }
$$

Equality constraints are 


$$
\begin{aligned}
& P_{g m}-P_{d m}=V_{m} \sum_{n=1}^{x}\left[G_{m n} \cos \left(\lambda_{m n}\right)+\right. \\
& B_{m n} \sin \left(\lambda_{m n}\right) \\
& Q_{g m}-Q_{d m}=V_{m} \sum_{n=1}^{x}\left[G_{m n} \cos \left(\lambda_{m n}\right)+\right. \\
& B_{m n} \sin \left(\lambda_{m n}\right)
\end{aligned}
$$

Different case studies under load flow studies are given below.

\section{Case 1: Without Congestion case}

Load flow is taken by using a Newton-raphson method. In this case congestion is not considered in the transmission line. In this case bus voltage (pu), bus powers, bus voltage angles, power flow in line, transformer rating, generation at different buses and load are given. Negative sign indicate the power flows in opposite direction.

\section{Case 2: Congestion case without TCSC}

In this case power flow through transformer which is connected between buses 5 and 6 is limited by considering congestion up to $36.120 \mathrm{MW}$ but the real power flows in a base case is 45.826 . In this case generation at different generating station gets changed. Line flow data is changed as compared to no congestion case.

\section{Case 3: Congestion case with TCSC}

In this case TCSC added between the buses 1 and 2 to reduce the losses in transmission line. Line flow data is changed from without TCSC case in congestion cases. The generator data for frequency dependent load is as same as without adding the TCSC but the bus voltages and other remaining data is changed. The single line diagram is shown in fig 10 .

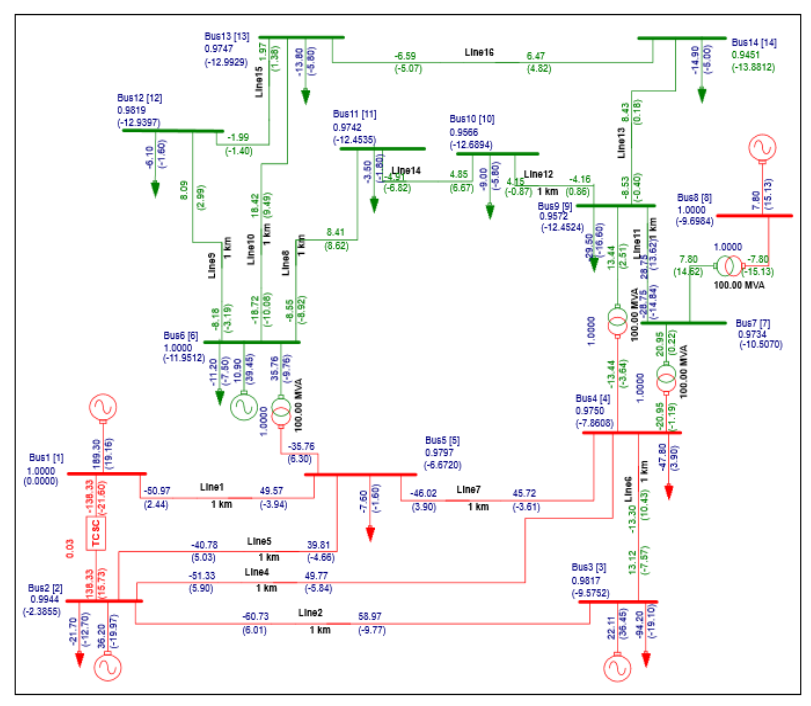

Figure 10. Single Line Diagram in Congestion Case with TCSC.

\section{Result and discussion}

In this section actual load flow analysis of three cases is taken. Load is same for all the cases. In case 1 when no congestion is considered the real and reactive power generated is 273.1477 MW and 101.1557 MVAr respectively. Real and reactive power losses in this case are 13.8480 MW and 27.5557 MVAr respectively. In case 2 when congestion is considered without TCSC device real and reactive power generated is $269.996 \mathrm{MW}$ and 89.539 MVAr respectively. Real and reactive power losses in this case are 10.6962 MW and 16.2692 MVAr respectively. In case 3 when congestion is considered with TCSC device real and reactive power generated is $266.310 \mathrm{MW}$ and 90.190 MVAr respectively. Real and reactive power losses are 7.0098 MW and 10.7254 MVAr respectively. It is obtained that when TCSC device is connected to transmission line system losses in the transmission system are get reduced. Line number shows the line connected between the buses. Real power losses for different cases are given in figure 11.

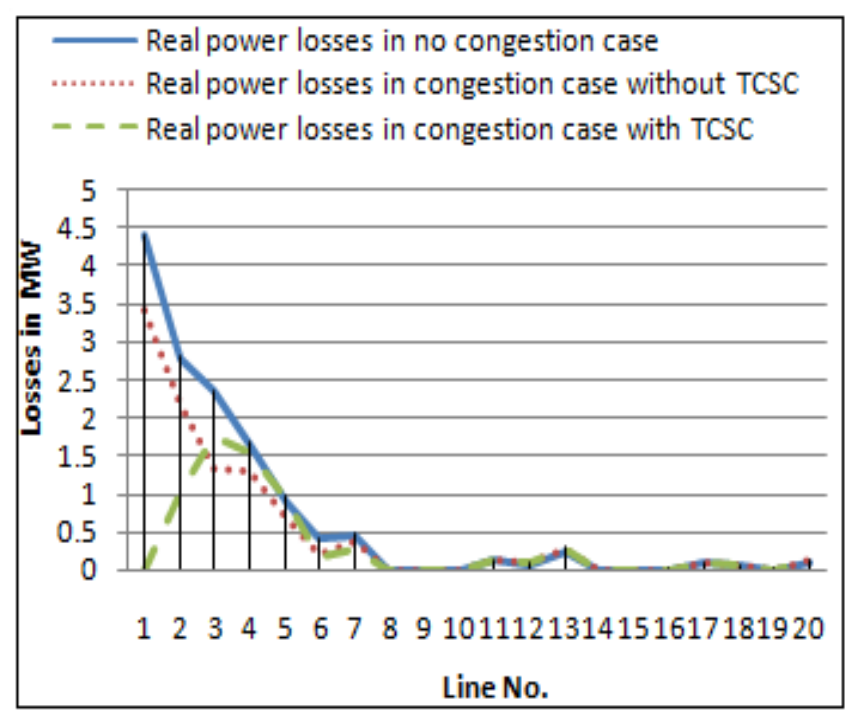

Figure 11. Real power losses in different cases.

The reactive power losses for different cases is shown in figure 12 .

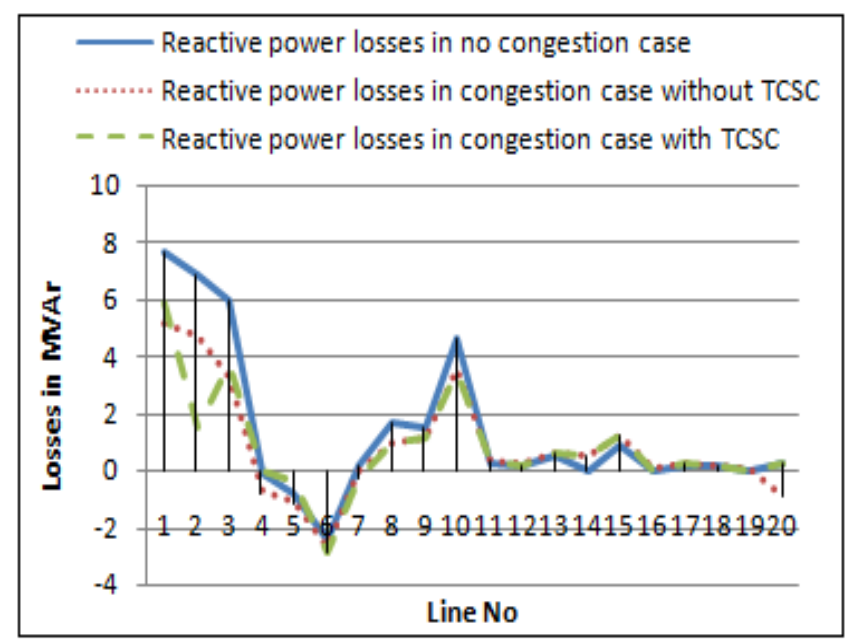

Figure 12. Reactive power losses in different cases. 
13 Real and Reactive power losses in various cases.

\begin{tabular}{|c|c|c|c|}
\hline $\begin{array}{c}\text { Total } \\
\text { Losses }\end{array}$ & $\begin{array}{c}\text { No } \\
\text { Congestion } \\
\text { case }\end{array}$ & $\begin{array}{c}\text { Congestion } \\
\text { case without } \\
\text { TCSC }\end{array}$ & $\begin{array}{c}\text { Congestion } \\
\text { case with } \\
\text { TCSC }\end{array}$ \\
\hline $\begin{array}{c}\text { Real power } \\
\text { losses } \\
\text { (MW) }\end{array}$ & 13.8479 & 10.6962 & 7.0098 \\
\hline $\begin{array}{c}\text { Reactive } \\
\text { power } \\
\text { losses } \\
\text { (MVAr) }\end{array}$ & 27.5556 & 16.2692 & 10.7254 \\
\hline
\end{tabular}

\section{CONClusion}

In this study market splitting based approach is used to manage the congestion and TCSC device has been used to reduce the losses in the transmission line. In case of congestion the deregulated system is split into different zones and zones have different prices. The results obtained by this research methodology are as given below. In this research work market splitting approach is used to manage the congestion and TCSC device has been used to reduce the losses in the transmission line. In case of congestion the deregulated system is divided into different zones and zones have different prices. Locational marginal prices (LMPs) are same at every bus in no congestion case ie 39.03 \$/MW-hr. To find the LPMs, DCOPF is done MATPOWER software and results are compared with program in MATLAB environment. LMPs in congestion case for with/without TCSC obtained by using MATPOWER. The system has divided into different zones on the basis of LMP values. Zone LMP value is calculated by taking average values of LMPs of all the buses in a single zone. Hence the market is clear at different prices. The prices are different for all the zones and same price for the buses in same zone. Load flow analysis (LFA) is taken on MIPOWER software to find the actual flow in a transmission system. By using a TCSC device losses are reduced up to $3 \mathrm{MW}$ in congestion case.

\section{REFERENCES}

[1] S.Meikandasivam, R. K. Nema, and S. K. Jain, "Selection of TCSC Parameters : Capacitor and Inductor," no. 2, 2011, pp. 1-5.

[2] M. Matcha et al., "Congestion management considering optimal placement of distributed generator in deregulated power system networks," IEEE Trans. Power Syst., vol 42, no. 1, 2010, pp. 1-8.

[3] A. S. Siddiqui, "Zonal Congestion Management Based on Locational Marginal Price in Deregulated Electricity Market,", 2015 pp. 3-6.

[4] N. Kirthika and S. Balamurugan, "Pass Through Congestion Management in Deregulated Power System Using Genetic Algorithm," 2017.

[5] A. K. R. K and S. P. Singh, "Congestion mitigation using UPFC," vol. 8687, pp. 2433-2442, 2016.

[6] F. Rahimi and A. Ipakchi, "Demand response as a market resource under the smart grid paradigm," IEEE Trans. Smart Grid, vol. 1, no. 1, 2010, pp. 82-88.

[7] A. J. Conejo, F. Milano, and R. García-Bertrand, "Congestion management ensuring voltage stability," IEEE Trans. Powe Syst. vol. 21 , no. 1,2006 , pp. 357-364.

[8] A. S. Siddiqui, R. Jain, M. Jamil, and C. P. Gupta, "LMP technique for locating series FACTS device (TCSC) for social welfare benefits in deregulated electricity market,"India Int. Conf. Power Electron.
IICPE, 2012.

[9] a. Kumar, S. C. Srivastava, and S. N. Singh, "A Zonal Congestion Management Approach Using Real and Reactive Power Rescheduling," IEEE Trans. Power Syst., vol. 19, no. 1, 2004, pp. 554-562.

[10] S. Dutta and S. P. Singh, "Optimal Rescheduling of Generators for Congestion Management Based on Particle Swarm Optimization," IEEE Trans. Power Syst., vol. 23, no. 4, 2008, pp. 1560-1569.

[11] K. Kaur, N. Kumar, S. Kumar, and K. Khatua, "Congestion management of transmission lines by FACTS devices using Krill herd technique," 2017 Innov. Power Adv. Comput. Technol. i-PACT 2017, vol. 2017-Janua, no. 1, 2018, pp. 1-8.

[12] M. Matcha and S. Kumari, "LMP Calculation wutg Distributed Loos using GA based DCOPF," J. Electr. Syst., vol. 8, no. 3, 2012, pp. 292-303.

[13] M. Oloomi Buygi, H. M. Shanechi, G. Balzer, and M. Shahidehpour, "Transmission planning approaches in restructured power systems," 2003 IEEE Bol. PowerTech - Conf. Proc., vol. 2, no. March, 2003, pp. 898-904.

[14] K. Singh, V. K. Yadav, N. P. Padhy, and J. Sharma, "Congestion management considering optimal placement of distributed generator in deregulated power system networks," Electr. Power Components Syst., vol. 42, no. 1, 2014, pp. 13-22.

[15] M. Sarwar and A. S. Siddiqui, "Congestion Management in Deregulated Electricity Market Using Distributed Generation," Ieee Indicon, no. 1, 2005, pp. 1-5.

[16] R. Leou and J. Teng, "A Transmission Plan Considering Uncertainties Under a Deregulated Market," vol. 6, 2011, pp. 33-37.

[17] M. Afkousi-Paqaleh, A. Abbaspour-Tehranifard, M. Rashidinejad and K. Lee, "Optimal placement and sizing of distributed resources for congestion management considering cost/benefit analysis," Power Energy Soc. Gen. Meet. 2010 IEEE, 2010, pp. 1-7.

[18] P. P. Kulkarni and N. D. Ghawghawe, "Optimal Placement and Parameter Setting of TCSC in Power Transmission System toIncrease the Power Transfer Capability," Int. Conf. Energy Syst. Appl., no. Icesa, 2015, pp. 735-739.

[19] S.E. Gasim and J. Jasni," Power System Security Enhancement and Loss Reduction using the SMART Power Flow Controller" ,IEEE Innovative smart grid Technologies - Asia (ISGT ASIA) ,2014,pp.307-311.

[20] N. A. Belyaev ; N. V. Korovkin ; V. S. Chudny , "Reduction of active power loss in electric power system with optimal placement of FACTS device", 2015 IEEE NW Russia Young Researchers in Electrical and Electronic Engineering Conference (EIConRusNW) 2015, pp. 150-154

[21] I. S. Latypov; V. V. Sushkov, reduction of active power loss in overhead power transmission lines rated for 6-35kv, 2016 Dynamics of Systems, Mechanisms and Machines (Dynamics), 2016,

[22] G. Hocine ; L. Fatiha ; F.Z Gherbi ; A. Labiba "The intrest of SACTS to improve voltage and loss reduction in the western Algerian network 2012", 2015 4th International Conference on Electrical Engineering (ICEE), 2012,pp.1-6.

[23] Junchao Ma ; Liqiang Yuan ; Zhengming Zhao ; Fanbo He," Transmission loss optimization-based optimal power floew strategy by hierarchical control for DC Microgrid",IEEE Transactions on Power Electronics, on power electronics, Year: Vol: 32 , Issue: 3, 2017, Pages: 1952 - 1963.

[24] M. Furuse ; S. Fuchino ; N. Higuchi ; I. Ishii," Feasibility study of Low-Voltage DC Superconducting Distribution system", IEEE Transaction on Applied Superconductivity, Vol. 15, 2005, Issue: 2.

[25] M.I. Alomoush," Derivation of UPFC DC load flow model with examples of its use in restructured power system", IEEE transaction of power system, Volume: 18 , Issue: 3,2003,Pages: 1173 - 1180.

[26] Ali Nourai ; V. I. Kogan ; Chris M. Schafer,"Load leveling reduces Transmission and distribution losses", IEEE Transactions on Power Delivery, Vol: 23 , Issue: 4, 2008, Pages: 2168 - 2173.

[27] C. Chompoo-inwai ; C. Yingvivatanapong ; P. Fuangfoo ; Wei-Jen Lee," Transmission Congestion Management During Transition $\checkmark$ Period of Electricity Deregulation in Thailand",IEEE Transactions on Industry Applications, ol: 43 , Issue: 6 Nov.-dec. 2007,1483-1490. 
[28] M. H. Moradi ; S. Dehghan; H. Faridi," Improving Zonal Congestion Relief Management using economical \& technical factors of the demand side", 2008 IEEE 2nd International Power and Energy Conference, 2007, pp: 1027-1032.

[29] A. Kumar ; S.N. Singh ; L.L. Lai," Impact of TCPAR on congestion clusters and congestion management using mixed integer nonlinear programming approach," 2006 IEEE Power Engineering Society General Meeting, 2006.

[30] M. M. Esfahani ; G. Yousefi " Real Time Congestion Management in Power Systems Considering Quasi-Dynamic Thermal Rating and Congestion Clearing Time", IEEE Transactions on Industrial Informatics,Vol: 12 , Issue: 2,2016,Pages: $745-754$.

[31] W. Liu ; Q. Wu ; F. Wen ; J. Østergaard,” Day-Ahead Congestion Management in Distribution Systems Through Household Demand Response and Distribution Congestion Prices", IEEE Transactions on Smart Grid,Vol: 5 , Issue: 6,2014,pp: 2739 - 2747.

\section{AUTHORS PROFILE}

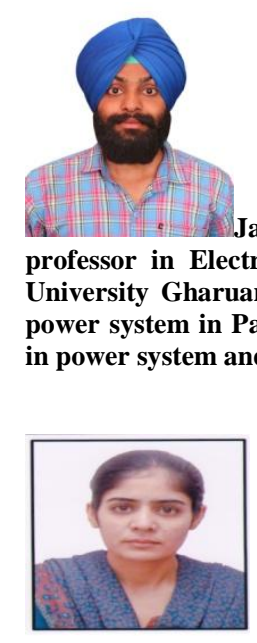

Jasjeet Singh is currently working as a assistant professor in Electrical Engineering Department, UIE, Chandigarh University Gharuan, Mohali, Punjab, India. He has done his ME in power system in Panjab University Chandigarh. His research interest in power system and renewable generation. Assistant professor in Electrical Engineering Department, UIE, Chandigarh University, Gharuan, Mohali, Punjab, India. She has 11 Years Experience in teaching. She is pursuing Phd. in Renewable energy Resources and smart Grid. She is the author of more than 50 Research Papers published in IEEE/Scopus/Springer National/international Journals and Conferences. 